\title{
Corrosion performances of micro-arc oxidation coatings on AZ31B, AZ80, and ZK60 cast Mg alloys
}

\author{
Yuna Xue $\mathrm{e}^{1,3}$ \\ ${ }^{1}$ School of Materials Science and Engineering \\ Xi'an University of Technology \\ Xi'an, China \\ xynlina@gmail.com \\ Bailing Jiang ${ }^{1}$ \\ jiangbail@vip.163.com
}

\author{
Xin Pang ${ }^{2}$ \\ ${ }^{2}$ CanmetMATERIALS \\ Natural Resources Canada \\ Hamilton, Canada \\ xin.pang@canada.ca \\ Hamid Jahed $^{3}$ \\ ${ }^{3}$ Department of Mechanical \& Mechatronics Engineering \\ University of Waterloo \\ Waterloo, Canada \\ hjahedmotlagh@uwaterloo.ca
}

\begin{abstract}
Micro-arc oxidation (MAO) technology is attractive for the surface treatment of $\mathrm{Mg}$ alloys for diverse applications because it can be used to form adherent coatings with superior wear and corrosion resistance. In the present study, the corrosion protective MAO coatings were prepared on the AZ31B, AZ80 and ZK60 cast magnesium alloy at a constant current mode in an alkaline silicate electrolyte. Analysis of the surface and cross-section morphology, phase composition and microstructures of the MAO coatings and these three kinds of substrates was conducted utilizing scanning electron microscope (SEM) and X-ray diffraction (XRD) techniques. The corrosion properties of the uncoated and MAO coated Mg alloys were investigated using advanced electrochemical methods including the open circuit potential (OCP) measurement and electrochemical impedance spectroscopy (EIS). To further characterize the protectiveness of the MAO coating, the scribed MAO coated AZ31B and ZK60 alloy coupons were exposed to the continuous salt spray corrosion testing (SSCT) for $168 \mathrm{~h}$. The experimental results show that the phase composition, the thickness and the microstructure of MAO coatings on different kinds of $\mathrm{Mg}$ alloys did not show any differences between them. While the MAO coating provides the best robust protection on the ZK60 $\mathrm{Mg}$ alloy substrate in the aqueous salt solution and continuous salt spray environments, the corrosion resistance increased by nearly three orders of magnitude as compared to uncoated $\mathrm{Mg}$ alloy.
\end{abstract}

Keywords-Cast magnesium alloys; Micro-arc oxidation; Electrochemical kinetic parameters; Scribe testing

\section{INTRODUCTION}

In the automotive industry, magnesium and magnesium alloys have been given priority to be the structural components to reduce the weight and decrease the fuel emissions [1]. As the application of magnesium alloys becoming mature, they are not only applied in the internal and unloading components, but also serviced in the external and loading parts [2,3]. However, magnesium alloy is prone to corrosion during services, which is a major factor in obstructing its application [4,5].

This paper discusses a promising surface treatment, microarc oxidation (MAO), to form the ceramic coatings on $\mathrm{Mg}$ and their alloys [6]. Up to now, the MAO coatings are widely used on different kinds of the magnesium alloy, which makes the perfect combination of the base material [7]. In this work, we chose two Mg-Al alloys (AZ31B and AZ80) and one Mg-Zn alloy (ZK60) as the substrate. Inclusion of Al can improve the corrosion resistance of magnesium alloy[8], and the zinc element with zirconium in $\mathrm{Mg}$ alloy has successful grain refinement and better anti-corrosion behavior [9]. For a better understanding of the correlations of MAO coatings, different substrate element alloys, corrosion kinetics in simulated service environment of automotive applications, the microstructure and corrosion properties of uncoated and MAO coated AZ31B, AZ80 and ZK60 were studied by the microscopic analysis and corrosion methods.

\section{MATERIALS AND EXPERIMENTS}

\section{A. Materials}

The materials were commercially available AZ31B [10,11], AZ80 [12] and ZK60 [9] cast Mg alloys (see Table 1). These alloys were cut into flat coupons with the dimensions of 50 $\mathrm{mm} * 25 \mathrm{~mm} * 3 \mathrm{~mm}$. And then all the specimens were ground with emery paper to achieve lower surface roughness.

The processing parameters for the MAO treatment are listed in Table 2. All MAO coatings were performed at Xi'an University of Technology. After the MAO treatment, the 
specimens were first cleaned with distilled water and then air dried for further analysis.

TABLE 1 Chemical composition of the substrate alloys

\begin{tabular}{|l|ccccccc|}
\hline \multirow{2}{*}{ Alloys } & \multicolumn{7}{|c|}{ Compositions (wt. \%) } \\
\cline { 2 - 8 } & $\boldsymbol{A l}$ & $\boldsymbol{Z n}$ & $\boldsymbol{Z r}$ & $\boldsymbol{M n}$ & $\boldsymbol{S i}$ & $\boldsymbol{C u}$ & $\boldsymbol{M g}$ \\
\hline AZ31B & 3.1 & 1.05 & 0.54 & 0.02 & 0.0008 & Balance \\
AZ80 & 8.4 & 0.48 & & 0.2 & 0.026 & 0.0026 & Balance \\
ZK60 & 5.2 & & 0.47 & 0.09 & 0.03 & 0.005 & Balance \\
\hline
\end{tabular}

TABLE 2 Processing parameters for the MAO treatment

\begin{tabular}{|c|c|}
\hline Electrolyte composition & $\begin{array}{l}\mathrm{Na}_{2} \mathrm{SiO}_{3}-5 \mathrm{~g} / \mathrm{L} ; \\
\mathrm{KF}-8 \mathrm{~g} / \mathrm{L} ; \\
\mathrm{KOH}-10 \mathrm{~g} / \mathrm{L}\end{array}$ \\
\hline Electrolyte $\mathrm{pH}$ & 13 \\
\hline Current density (mA/cm2) & 34 \\
\hline Power supply pulse width $(\mu \mathrm{s})$ & 80 \\
\hline Processing time $(\mathrm{min})$ & 5 \\
\hline Power supply average current(A) & 1 \\
\hline
\end{tabular}

\section{B. Specimen examination and test methods}

For metallographic characterization of the base alloys, optical microstructure of the specimens were studied using the etching reagents, and the etching procedure was immersing specimen face up with gentle agitation until face turns brown. The surface and cross-section morphologies of the MAO coated different substrate were investigated by XL30 SEM. And phase composition of uncoated and MAO coated specimens was identified by XRD analysis.

The electrochemical measurements including open-current potential (OCP) and electrochemical impedance spectroscopy (EIS) were obtained using a Solartron Analytical 1287A potentiostat/galvanostat and Solartron 1255B Frequency Response Analyzer controlled by a personal computer at room temperature in the corrosive medium $3.5 \mathrm{wt} \% \mathrm{NaCl}$ solution.

The scribe test were conducted in the Singleton Corp.SCCH-salt fog chamber to a static environment of continuous salt spray with a concentration of $5 \mathrm{wt} \% \mathrm{NaCl}$ at $36{ }^{\circ} \mathrm{C}, 100 \%$ relative humidity according to ASTM B117 [13]. MAO coated AZ31B and ZK60 contained a vertical scribe parallel to major long axis (about $3.5 \mathrm{~cm}$ in length) down the centerline. Scribing was performed by rounded tip scribing tool to make sure that fresh $\mathrm{Mg}$ alloy substrate metal was exposed. The rust creepage along the scribe after corrosion testing was evaluated.

\section{RESULTS AND DISCUSSION}

\section{A. Materials characterization}

Fig.1 shows the optical micrographs of the internal structure for the AZ31B, AZ80 and ZK60 cast magnesium alloys. For $\mathrm{AZ31B}$, the volume fraction ratio of the $\beta-\mathrm{Mg}_{17} \mathrm{Al}_{12}$ is low and it is diffused in the matrix $\alpha-\mathrm{Mg}$ because of the low aluminum content as shown in the Fig.1a. In the AZ80 alloy, the higher content of $\mathrm{Al}$ element, the richer $\beta$-phase formed a continuous network and precipitated along the grain boundaries. There are $\mathrm{MgZn}_{2}$ and $\mathrm{Zn}_{2} \mathrm{Zr}$ intermetallic compound in the
ZK60 alloy (shown in Fig.1c,d). The zirconium in ZK60 magnesium alloys can refine grain and purify the composition of alloy [14].
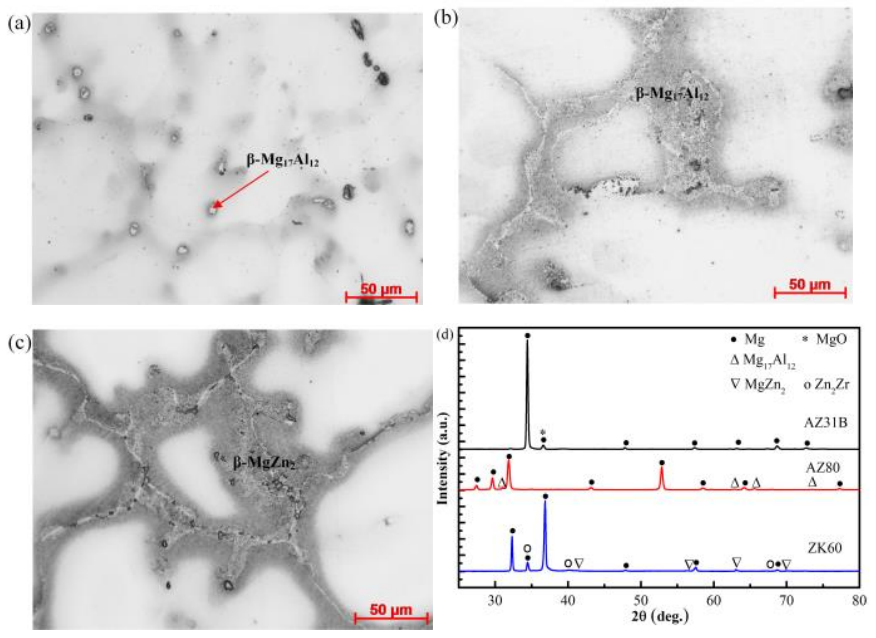

Figure 1. Optical micrographs (a,b,c) and XRD patterns (d) of the AZ31B, AZ80 and ZK60 Mg alloys

SEM images and phase compositions of the typical surface of the MAO coated magnesium alloys are shown in Fig.2. The surface of the MAO treated different $\mathrm{Mg}$ alloys under same processing parameters were featured by a porous morphology with lots of volcano top-like micro-pores which diameter is about $1 \mu \mathrm{m}$, dense and uniform ceramic coating with strong adhesion to substrate are formed on the substrates. There is no obvious difference between the surface micrographs of these three specimens. The thickness of the MAO coatings is about $5.5 \mu \mathrm{m}$, and a typical amount of micro-pores and micro-cracks can still be found in the coatings. Seen from the XRD spectra, it is clear that the surface of all treated specimens are mainly composed of $\mathrm{Mg}$ phase, $\mathrm{MgO}, \mathrm{MgF}_{2}$ and $\mathrm{Mg}_{2} \mathrm{SiO}_{4}$. And they also contained some complex silicate compounds $\mathrm{Mg}_{3} \mathrm{Al}_{2}\left(\mathrm{SiO}_{4}\right)_{3}$ and $\mathrm{Mg}_{\mathrm{x}} \mathrm{F}_{\mathrm{y}}\left(\mathrm{SiO}_{4}\right)_{\mathrm{z}}$.
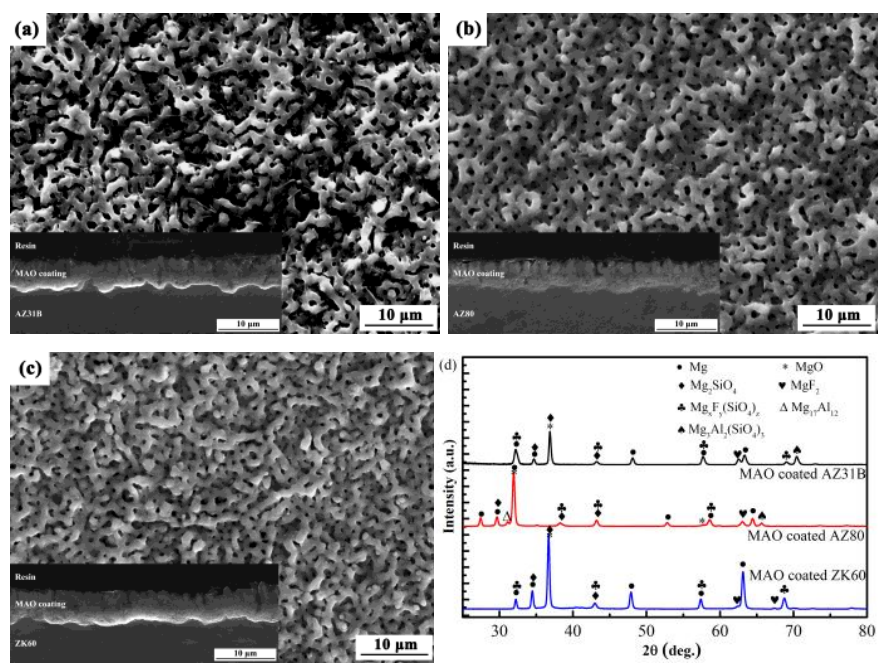

Figure 2. SEM images of the surface, cross-sectional morphology and the corresponding phase compositions (d) of the MAO coated (a) AZ31B, (b) AZ80 and (c) ZK60 Mg alloys 


\section{B. Electrochemical corrosion test}

\section{1) $\mathrm{OCP}$}

Fig. 3 shows the OCPs of these different specimens. After $30 \mathrm{~min}$ of immersion, all these specimens were reached to the relatively stable values of electrode potentials. Compared with the bare substrate, the OCPs of the specimens with MAO coated Mg alloys were shifted towards the noble direction. The uncoated $\mathrm{Mg}$ specimens had a low average OCP value of -1.54 , -1.52 and $-1.49 \mathrm{~V}$ for AZ31B, AZ80 and ZK60 Mg alloy, respectively. In contrast, all the MAO coated AZ31B, AZ80 and ZK60 specimens showed more noble average OCP values, which were $-1.29,-1.28$ and $-1.26 \mathrm{~V}$, respectively. These results suggest that MAO deposited on magnesium alloys showed a better thermodynamically stable and can improve the corrosion resistance of magnesium alloys in a dilute chloride solution.

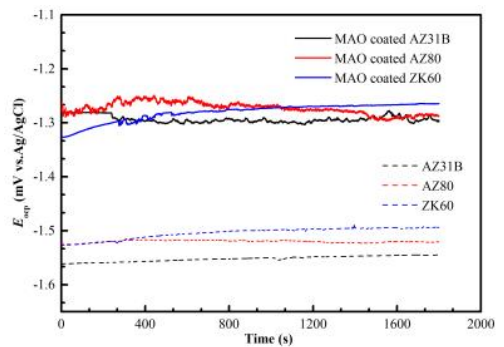

Figure 3. OCPs vs. immersion time curves in $3.5 \mathrm{wt} \% \mathrm{NaCl}$ solution for uncoated and MAO coated different $\mathrm{Mg}$ alloys

\section{2) $E I S$}

Fig.4 shows the plots of impedance modulus vs. frequency and phase angle vs. frequency measured after the OCP test for the MAO coated and bare magnesium alloys. The equivalent circuits seen in Fig.5 were used to simulate the measured impedance data of the uncoated and MAO coated Mg alloys, and it shows the charge transfer between the reference electrode and working electrode during the corrosion process.
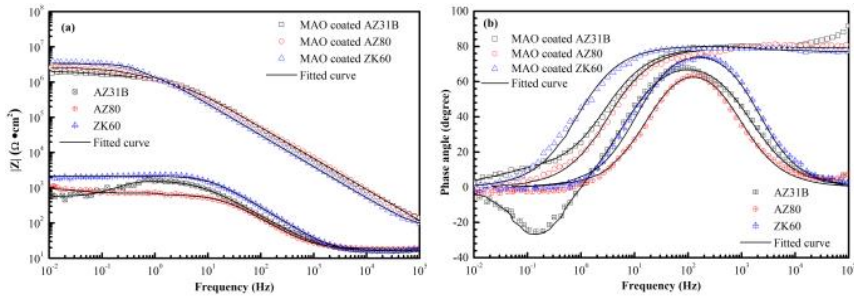

Figure 4. EIS experimental data and simulated curves for coated and uncoated Mg alloys specimens in the form of Bode plots: (a) impedance modulus vs. frequency, and (b) phase angle vs. frequency plots
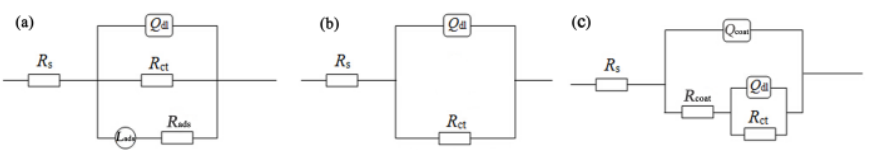

Figure 5. Equivalent electrical circuits for (a) AZ31B, (b) AZ80 and ZK60 and (c) MAO coated AZ31B, AZ80 and ZK60 alloys

For the substrate AZ31B Mg alloy, Fig.5 shows the adsorption inductance behavior in the low frequency range (less than $100 \mathrm{~Hz}$ ) of the spectrum. Its equivalent circuit (Fig.5a) is made up of the electrolyte resistance $\left(R_{\mathrm{s}}\right)$, charge transfer resistance $\left(R_{\mathrm{ct}}\right)$ of the double-layer capacitor and double-layer capacitance $\left(Q_{\mathrm{dl}}\right)$ which are attributed to the Faradaic processes [15], adsorption resistance $\left(R_{\mathrm{ads}}\right)$ and adsorption inductance $\left(L_{\text {ads }}\right)$ which are associated with either the corrosion products such as $\mathrm{MgO} / \mathrm{Mg}(\mathrm{OH})_{2}$ formed on the surface of $\mathrm{Mg}$ alloy or $\mathrm{Mg}$ dissolution in chloride containing solution. In AZ80 and ZK60 alloy, their equivalent circuit includes $R_{\mathrm{s}}, R_{\mathrm{ct}}$ and $Q_{\mathrm{dl}}$. The proposed equivalent circuit of MAO coated Mg alloys is shown in Fig.5c. It consists of $R_{\mathrm{s}}, R_{\mathrm{ct}}$ and $Q_{\mathrm{dl}}$, coating resistance $\left(R_{\text {coat }}\right)$ and coating capacitance $\left(Q_{\text {coat }}\right)$ which is the virtual properties of MAO coating [16]. It can be seen from Fig.4 that the simulated curves fit very well with the experiment data. The fitting results are summarized in Table 3.

TABLE 3 Results of fitting EIS data for the uncoated and MAO coated Mg alloys specimens

\begin{tabular}{|c|c|c|c|c|c|c|c|}
\hline Specimen & $\begin{array}{l}R_{\mathrm{ct}} \\
\left(\Omega \cdot \mathrm{cm}^{2}\right)\end{array}$ & $\begin{array}{l}Q_{\mathrm{dl}} \\
\left(\mu \mathrm{F} / \mathrm{cm}^{2} \cdot \mathrm{s}^{1-\mathrm{n}}\right)\end{array}$ & & $\begin{array}{l}R_{\text {ads }} \\
\left(\Omega \cdot \mathrm{cm}^{2}\right)\end{array}$ & $\begin{array}{l}\begin{array}{l}\text { ads } \\
\left(\mathrm{H} / \mathrm{cm}^{2}\right)\end{array} \\
\end{array}$ & & $\begin{array}{l}R_{\text {total }} \\
\left(\Omega \cdot \mathrm{cm}^{2}\right)\end{array}$ \\
\hline AZ31B & $1.59 \times 10^{3}$ & 23.59 & 0.864 & 870 & 1415 & & $2.459 \times 10^{3}$ \\
\hline AZ80 & $3.31 \times 10^{3}$ & 18.92 & 0.901 & & & & $3.307 \times 10^{3}$ \\
\hline ZK60 & $6.34 \times 10^{3}$ & 8.72 & 0.938 & & & & $6.335 \times 10^{3}$ \\
\hline Specimen & $\begin{array}{l}R_{\text {coat }} \\
\left(\Omega \cdot \mathrm{cm}^{2}\right)\end{array}$ & $\begin{array}{l}Q_{\text {coat }} \\
\left(\mu \mathrm{F} / \mathrm{cm}^{2} \cdot \mathrm{s}^{1-\mathrm{n}}\right)\end{array}$ & $\mathrm{n}_{\text {coat }}$ & $\begin{array}{l}R_{\mathrm{ct}} \\
\left(\Omega \cdot \mathrm{cm}^{2}\right)\end{array}$ & $\begin{array}{l}Q_{\mathrm{dl}} \\
\left(\mu \mathrm{F} / \mathrm{cm}^{2} \cdot \mathrm{s}^{1-\mathrm{n}}\right)\end{array}$ & $\mathrm{n}_{\mathrm{dl}}$ & $\begin{array}{l}R_{\text {total }} \\
\left(\Omega \cdot \mathrm{cm}^{2}\right)\end{array}$ \\
\hline $\begin{array}{c}\text { MAO } \\
\text { coated } \\
\text { AZ31B }\end{array}$ & $7.97 \times 10^{5}$ & 0.066 & 0.885 & $1.34 \times 10^{6}$ & 0.186 & 0.856 & $2.141 \times 10^{6}$ \\
\hline $\begin{array}{l}\text { MAO } \\
\text { coated } \\
\text { AZ80 }\end{array}$ & $8.28 \times 10^{5}$ & 0.040 & 0.859 & $2.10 \times 10^{6}$ & 0.103 & 0.883 & $2.929 \times 10^{6}$ \\
\hline $\begin{array}{l}\text { MAO } \\
\text { coated } \\
\text { ZK60 }\end{array}$ & $2.10 \times 10^{6}$ & 0.010 & 0.847 & $3.54 \times 10^{6}$ & 0.068 & 0.895 & $5.645 \times 10^{6}$ \\
\hline
\end{tabular}

In this work, a $R_{\text {ads }}$ of $870 \Omega \cdot \mathrm{cm}^{2}$ was obtained for the uncoated AZ31B alloy specimen. In comparison, 3-4 orders of magnitude higher coating resistance $R_{\text {coat }}\left(7.97 \times 10^{5} \sim 2.10 \times 10^{6}\right.$ $\Omega \cdot \mathrm{cm}^{2}$ ) than the $R_{\text {ads }}$ of uncoated AZ31B Mg alloy were obtained for the MAO coated specimens. It is suggested that the formation of complex compounds consisting of mainly $\mathrm{Mg}_{2} \mathrm{SiO}_{4}$ and $\mathrm{MgF}_{2}$ on the alloy surface during the MAO process improved the corrosion resistance of the alloy significantly. The high $R_{\text {coat }}$ and low $Q_{\text {coat }}$ indicate a small number of ionic conducting pathways (pores and micro-cracks) in the MAO coating, especially for the MAO coated ZK60 Mg alloy. It should be noted that for all coated specimens the charge transfer resistance $R_{\text {ct }}$ obtained is always higher than coating resistance $R_{\text {coat }}$, indicating that the charge transfer through the electrical double-layer at the coating/substrate interface is also pronouncedly impeded by the MAO coating, leading to improve the corrosion resistance of the MAO coated $\mathrm{Mg}$ alloy specimens.

For the charge transfer resistance $\left(R_{\mathrm{ct}}\right)$, it can be acquired from the high-frequency range and correspond to the dissolution of magnesium alloy and can directly characterize the corrosion resistance of the specimens. As shown in Table 3, the MAO coated ZK60 Mg alloy specimen has a very high $R_{\mathrm{ct}}$ $\left(3.54 \times 10^{6} \Omega \cdot \mathrm{cm}^{2}\right)$ and low $Q_{\mathrm{dl}}\left(0.068 \mu \mathrm{F} / \mathrm{cm}^{2} \cdot \mathrm{s}^{1-\mathrm{n}}\right)$ compared with other coated specimens. This can be attributed to the more compact coating microstructure and elements with more positive potential obtained under such a processing condition. It is worth noticing that the polarisation resistance $R_{\text {total }}$ 
$\left(R_{\text {total }}=R_{\text {coat }}+R_{\text {ct }}\right.$ for MAO coated $\mathrm{Mg}$ alloys specimens, $R_{\text {total }}=R_{\text {ads }}+R_{\mathrm{ct}}$ for uncoated AZ31B specimen, and $R_{\mathrm{total}}=R_{\mathrm{ct}}$ for uncoated AZ80 and ZK60 specimens) measured by EIS, as listed in Table 3, follows such an order: MAO coated ZK60 > MAO coated AZ80 > MAO coated AZ31B; for bare alloys: ZK60 > AZ80 > AZ31B. The polarisation resistance from EIS has been widely used to account for the kinetics of electrochemical corrosion process [17]. The higher polarisation resistance, the better corrosion resistance the coated specimen exhibits.

\section{Scribe testing}

Fig. 6 shows the photographs of the MAO coated AZ31B and ZK60 specimens after $0 \mathrm{~h}, 72 \mathrm{~h}$ and $168 \mathrm{~h}$ exposure in the ASTM B117 test environment. After $72 \mathrm{~h}$, visual corrosion damage associated with the scribe was observed on the MAO coated AZ31B alloy. None of the MAO coated ZK60 alloy exhibited any visual corrosion damage associated with the scribe. As the corrosion continues (168 h), MAO coated AZ31B specimen exhibited significantly more corrosion products relative to the MAO coated ZK60 alloy. And there are some corrosion areas occurred on the MAO coated AZ31B alloy. The visual extent of the adherent corrosion product was significantly less than the MAO coated ZK60.

(a) MAO coated AZ31B

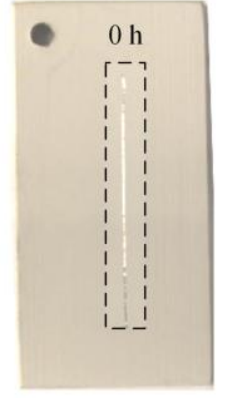

(b) MAO coated ZK60

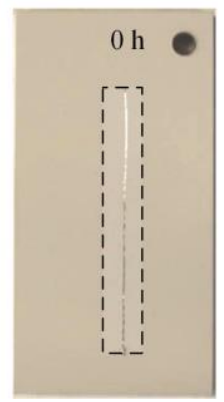

Figure 6. Photographs of the scribed MAO coated (a) AZ31B and (b) ZK60 specimens before corrosion and after ASTM B117 testing for $72 \mathrm{~h}$ and $168 \mathrm{~h}$

It seems that the spread of corrosion from scribe was influenced more by the difference in the coating substrate. Combining the microstructure and electrochemical corrosion results, in AZ series and ZK60 alloys, the corrosion mechanism was more influenced by the $\mathrm{Al}, \mathrm{Zn}$ distribution and morphology of the formed $\beta$-phase. The highest corrosion resistance of ZK60 among these three alloys is related to $\mathrm{Zn}$ and $\mathrm{Zr}$ elements which can form the compounds of $\mathrm{MgZn}_{2}$ and $\mathrm{Zn}_{2} \mathrm{Zr}$ [18]. For MAO coating, the MAO coated $\mathrm{Mg}$ alloys exhibited excellent corrosion performances due to the protection of the MAO coatings containing $\mathrm{Mg}_{2} \mathrm{SiO}_{4}$ and $\mathrm{MgF}_{2}$ phases that have relatively stable chemical properties [19]. Under the same MAO processing parameters, there is not much difference between the thickness and density of the coating on different substrate. When the coating is broken down, its corrosion is mainly depended on the substrate properties. After the scribe testing, the MAO coating on ZK60 specimen exhibited better corrosion protection in the continuous slat spray environment than that synthesized on the AZ31B alloy.

\section{CONCLUSIONS}

In this work, the significance of the microstructure and corrosion properties of the MAO coated different kinds of magnesium alloys were evaluated using advance microstructural and surface analysis techniques, electrochemical testing method and scribe testing exposure in the ASTM B117 test environment. The conclusions can be summarized as:

1) The corrosion behavior of the three kinds of cast magnesium alloy of AZ31B, AZ80 and ZK60 has shown that the ZK60 Mg alloy is better than AZ80 and AZ31B.

2) Adherent, dense and uniform MAO coatings are grown on AZ31B, AZ80 and ZK60 Mg alloy substrates in an alkaline silicate electrolyte. SEM and XRD analysis has shown that the MAO coating is a complex mixture of compounds including $\mathrm{MgO}, \mathrm{Mg}_{2} \mathrm{SiO}_{4}$ and $\mathrm{MgF}_{2}$, etc. The variation of different substrate materials did not result in any marked change in the compositional or phase composition and the thickness, microstructure of the MAO coating.

3) MAO coatings provide robust protection of the AZ31B, AZ80 and ZK60 Mg alloys substrate in both electrochemical and scribe salt spray corrosion tests. The MAO coated ZK60 exhibited better anti-corrosion performance among these specimens.

\section{ACKNOWLEDGMENT}

The technical support of Chao Shi of CanmetMATERIALS, Natural Resources Canada, Dr. Sugrib Shaha and Jie Wang of the University of Waterloo during the course of this work is gratefully acknowledged.

\section{REFERENCES}

[1] A.A. Luo, "Magnesium: current and potential automotive applications," Jom., vol. 54, 2002, pp. 42-48.

[2] S. Dayani, S. Shaha, R. Ghelichi, J. Wang, H. Jahed, "The impact of AA7075 cold spray coating on the fatigue life of AZ31B cast alloy," Surf. Coat. Technol., vol. 337, 2018, pp.150-158.

[3] D. Toscano, S. Shaha, B. Behravesh, H. Jahed, B. Williams, "Effect of forging on microstructure, texture, and uniaxial properties of cast AZ31B alloy," J. Mater. Eng. Perform., vol. 26, 2017, pp. 3090-3103.

[4] I.J.Polmear, "Magnesium alloys and applications," Mater. Sci. Technol., vol. 10, 1994, pp. 1-16.

[5] M. Diab, X. Pang, H. Jahed, "The Effect of pure aluminum cold spray coating on corrosion and corrosion fatigue of magnesium (3\% Al-1\% Zn) extrusion," Surf. Coat. Technol., vol. 309, 2017, pp.423-435.

[6] F.C Walsh, C.T.J. Low, R.J.K. Wood, K.T. Stevens, J. Archer, A.R. Poeton, A. Ryder, "Plasma electrolytic oxidation (PEO) for production of anodised coatings on lightweight metal (Al, Mg, Ti) alloys," Trans. 
IMF., vol. 87, 2009, pp.122-135.

[7] B. Vladimirov, B. Krit, V. Lyudin, N. Morozova, A. Rossiiskaya, I. Suminov, A. Epel'feld, "Microarc oxidation of magnesium alloys: A review," Surf. Eng. Appl. Electrochem., vol. 50, 2014, pp.195-232.

[8] A. Pardo, M. Merino, A. Coy, F. Viejo, R. Arrabal, S. Jr, "Influence of microstructure and composition on the corrosion behaviour of $\mathrm{Mg} / \mathrm{Al}$ alloys in chloride media, Electrochim. Acta., vol.53, 2008, pp.78907902.

[9] S. Karparvarfard, S. Shaha, S. Behravesh, H. Jahed, B. Williams, "Microstructure, texture and mechanical behavior characterization of hot forged cast ZK60 magnesium alloy," J. Mater. Sci. Technol., vol. 33, 2017, pp.907-918.

[10] D. Toscano, S. Shaha, B. Behravesh, H. Jahed, B. Williams, "Effect of forging on the low cycle fatigue behavior of cast AZ31B alloy," Mater. Sci. Eng. A, vol. 706, 2017, pp.342-356.

[11] S. Behravesh, H. Jahed, S. Lambert, "Characterization of magnesium spot welds under tensile and cyclic loadings," Mater. Des., vol. 32, 2011, pp.4890-4900.

[12] A. Gryguc, S. Shaha, S. Behravesh, H. Jahed, M. Wells, B. Williams, X. $\mathrm{Su}$, "Monotonic and cyclic behaviour of cast and cast-forged AZ80 Mg, Int. J. Fatigue, vol. 104, 2017, pp.136-149.

[13] S.P. "ASTM, B 0117 Operating Salt Spray (Fog) Apparatus, Astm."
2011, pp.1-12.

[14] J. Robson, C. Paa-Rai, "The interaction of grain refinement and ageing in magnesium-zinc-zirconium (ZK) alloys," Acta Mater., vol.95, 2015, pp.10-19.

[15] V. Ezhilselvi, J. Nithin, J.N. Balaraju, S. Subramanian, "The influence of current density on the morphology and corrosion properties of MAO coatings on AZ31B magnesium alloy," Surf. Coat. Technol., vol. 288 2016, pp.221-229.

[16] H.S. Ryu, J. Ryu, D. Park, S. Hong, "Electrochemical corrosion properties of nanostructured YSZ coated AZ31 magnesium alloy prepared by aerosol deposition, J. Electrochem. Soc., 2011, pp.23-28.

[17] J. Jorcin, M. Orazem, N. Pébère, B. Tribollet, "CPE analysis by local electrochemical impedance spectroscopy," Electrochim. Acta., vol. 51, 2006, pp.1473-1479.

[18] G. Song, A. Atrens, "Corrosion Mechanisms of Magnesium Alloys," Adv. Eng. Mater., vol. 1, 1999, pp.11-33.

[19] Y. Wang, Z. Huang, Q. Yan, C. Liu, P. Liu, Y. Zhang, C. Guo, G. Jiang, D. Shen, "Corrosion behaviors and effects of corrosion products of plasma electrolytic oxidation coated AZ31 magnesium alloy under the salt spray corrosion test," Appl. Surf. Sci., vol. 378, 2016, pp.435-442. 